\title{
Clinical Trial Adjudication Committee Document
}

National Cancer Institute

\section{Source}

National Cancer Institute. Clinical Trial Adjudication Committee Document. NCI

Thesaurus. Code C115644.

Records describing the Adjudication Committee's evaluation process of key events in a clinical trial. 